\title{
Desenvolvimento de um Método por CLAE Multidimensional para o Monitoramento Online da Atividade da Enzima IMPDH-Mt
}

\author{
Mariana Delle Piane de Carvalho \& Marcela Cristina de Moraes
}

A tuberculose é uma doença infecciosa causada pelo M.tuberculosis e pode ser fatal. A necessidade por novos fármacos para o tratamento da tuberculose é evidenciada pela complexidade e toxidez dos tratamentos disponíveis, bem como pela emergência de cepas multi-resistentes. Portanto, neste trabalho, é descrito o desenvolvimento e validação de um método por CLAE multidimensional para o monitoramento da atividade da enzima IMPDH de M. tuberculosis imobilizada.

Palavras Chave: Inosina Monofosfato Desidrogenase; Cromatografia Líquida; Tuberculose.

Tuberculosis (TB) is an infectious disease caused by Mycobacterium tuberculosis and can be fatal. New TB drugs are needed due to the complexity and toxicity of current drug regimens, as well as the emergence of multi-resistant strains. Therefore, in this work, we describe the development and validation of a multidimensional HPLC method to monitor on line the activity of the IMPDH from M. tuberculosis immobilized enzyme.

Keywords: Inosine Monophosphate Dehydrogenase; Liquid Chromatography; Tuberculosis. 
A tuberculose humana (TB) é uma doença causada principalmente pela micobactéria Mycobacterium tuberculosis que pode ser fatal. Ainda se observa uma alta taxa de mortalidade devido a esta doença, relacionada principalmente ao surgimento de cepas resistentes e a coinfecção com o vírus da AIDS.

A Inosina Monofosfato Desidrogenase (IMPDH) é uma enzima chave na via de salvação de purinas, da qual o M.tuberculosis é altamente dependente para a obtenção de nucleotídeos. Portanto, esta enzima é um alvo atrativo a ser estudado na busca de potenciais novas substâncias bioativas para o tratamento da tuberculose. Na figura 1 é representada a reação catalisada pela enzima IMPDH.

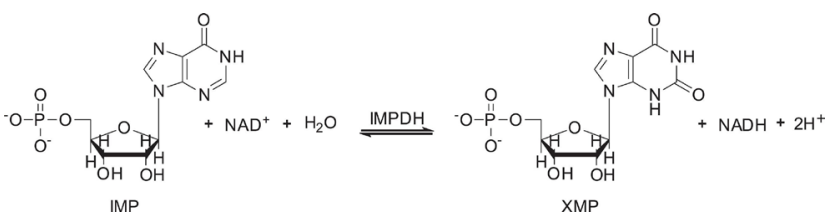

Figura 1. Reação catalisada pela enzima IMPDH. ${ }^{1}$

Este trabalho tem como objetivo o desenvolvimento e validação de um método analítico por CLAE multidimensional para o monitoramento online da atividade da IMPDH imobilizada, visando o desenvolvimento de um método de triagem automatizado, eficiente e robusto para a identificação de novos inibidores enzimáticos como potenciais protótipos de medicamentos para o tratamento da tuberculose.

\section{Metodologia}

A primeira etapa do desenvolvimento do método consistiu-se em determinar o tempo de acoplamento, que é o tempo em que o capilar contendo a enzima imobilizada deveria estar acoplado a coluna cromatográfica do sistema que fornecerá a separação dos produtos e substratos da reação catalisada pela enzima. Este tempo foi determinado através da injeção de uma solução com a mistura de substratos e produtos catalisados pela enzima e como mostrados na tabela 1 foi de 0,7 a $9,00 \mathrm{~min}$.
Tabela 1. Bomba 1: $0,05 \mathrm{~mL} / \mathrm{min}$, eluente A: tampão TRIS $50 \mathrm{mM}: \mathrm{KCl}$ $200 \mathrm{mM} \mathrm{pH} 8,5$. Bomba 2: $0,9 \mathrm{~mL} / \mathrm{min}$, eluente B: TEA pH 6,0:ACN (96:4).

\begin{tabular}{|c|c|c|c|}
\hline $\begin{array}{c}\text { Bomba } \\
\text { (Eluente) }\end{array}$ & $\begin{array}{c}\text { Tempo } \\
(\mathrm{min})\end{array}$ & Evento & $\begin{array}{c}\text { Posição da } \\
\text { Válvula }\end{array}$ \\
\hline $1(\mathrm{~A})$ & $0,0-0,7$ & $\begin{array}{c}\text { Eluição dos } \\
\text { analitos }\end{array}$ & 1 \\
\hline $2(\mathrm{~B})$ & $0,0-0,7$ & $\begin{array}{c}\text { Condicionamento } \\
\text { da coluna } \\
\text { analítica }\end{array}$ & 1 \\
\hline $1(\mathrm{~A})$ & $0,7-9,0$ & $\begin{array}{c}\text { Transferência dos } \\
\text { analitos para a } \\
\text { coluna analítica }\end{array}$ & 2 \\
\hline $1(\mathrm{~A})$ & $9,0-20,0$ & $\begin{array}{c}\text { Condicionamento } \\
\text { do IMP-IMER }\end{array}$ & 1 \\
\hline 2 (B) & $9,0-20,0$ & $\begin{array}{c}\text { Análise dos } \\
\text { compostos pela } \\
\text { coluna analítica }\end{array}$ & 1 \\
\hline
\end{tabular}

$\mathrm{O}$ método multidimensional consiste em inserir o capilar na 1 dimensão onde utiliza-se como FM o tampão de máxima atividade e estabilidade da enzima que contem TRIS: $\mathrm{KCl}$ a uma vazão baixa que permite a catálise enzimática.

Na segunda dimensão do sistema é utilizada uma coluna C18 e uma fase móvel constituída por solução $1 \%$ de TEA pH 6,0 : ACN (96:4) que permite a separação dos analitos, como pode ser observado no cromatograma.

Dessa forma as duas dimensões do sistema trabalham independentemente como pode ser observado na figura 2 estando acopladas apenas para a transferência dos analitos da primeira dimensão para a segunda dimensão.

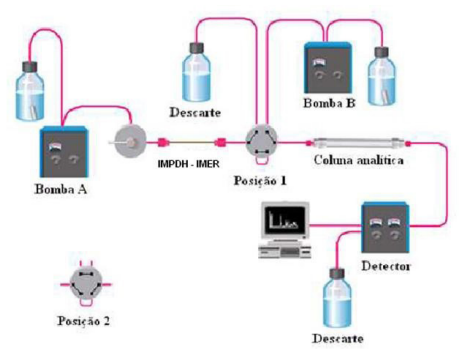

Figura 2. Representação do sistema cromatográfico multidimensional usado com o IMER na primeira dimensão e a coluna analítica na segunda dimensão. 
Após o desenvolvimento e otimização dos parâmetros cromatográficos, realizou-se a validação do método da metodologia analítica através da avaliação da linearidade, seletividade, precisão, exatidão, robustez, limites de detecção e quantificação, conforme preconizado pela Anvisa. $^{2}$

\section{Resultados e Discussão}

Os substratos e produtos da reação catalisada pela IMPDH-Mt absorvem na mesma região do UV, e o capilar de sílica fundida contendo a enzima imobilizada não possui resolução cromatográfica para a separação dos analitos, como pode ser observado na figura 3. Por isso, faz-se necessário o uso da cromatografia liquida multidimensional.

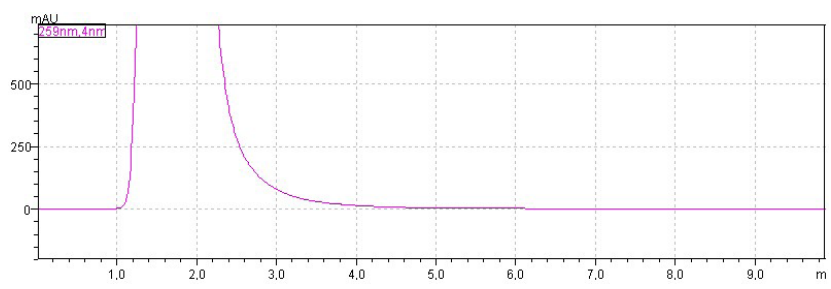

Figura 3. Cromatograma de determinação do tempo de acoplamento.

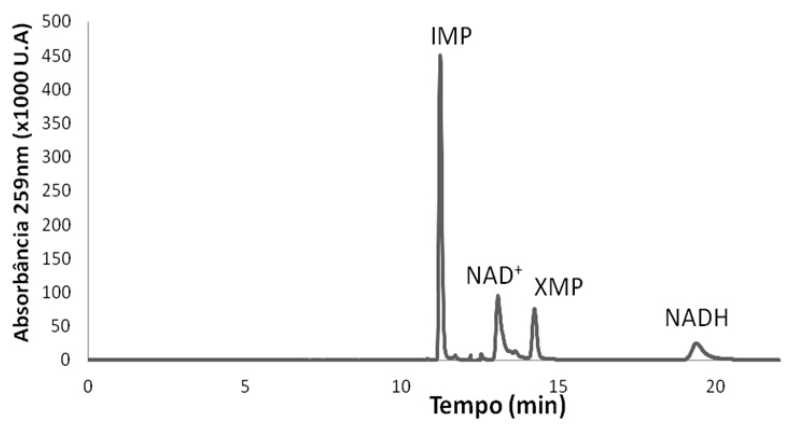

Figura 4. Separação cromatográfica de IMP $(\operatorname{tr}=10,8 \mathrm{~min}), \mathrm{NAD}+(\operatorname{tr}=$ $12,1 \mathrm{~min}), \mathrm{XMP}(\operatorname{tr}=13,0 \mathrm{~min})$ e $\mathrm{NADH}(\operatorname{tr}=16,7 \mathrm{~min}) ., \mathrm{Vinj}=10 \mu \mathrm{L}$.
O método desenvolvido foi validado de acordo com os parâmetros da Anvisa, avaliando-se a linearidade no intervalo de concentração de 5-320 $\mu \mathrm{M}$ (R2=0,9996), seletividade, precisão (0,38-4,39\%), exatidão (98,3$106,7 \%)$, limites de quantificação $(5,0 \mu \mathrm{M})$ e detecção $(0,05 \mu \mathrm{M}){ }^{2}$

A curva de calibração obtida é representada na figura 5.

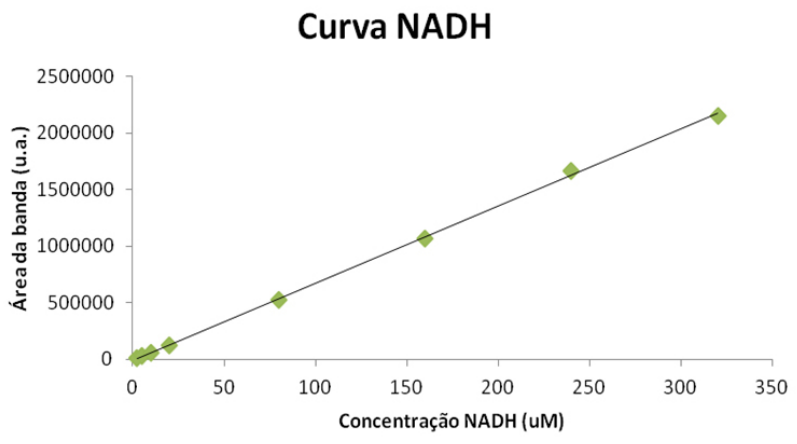

Figura 5. Curva de calibração para a quantificação de NADH.

\section{Conclusões}

O método cromatográfico multidimensional desenvolvido para o monitoramento on line da atividade da enzima IMPDH-Mt através da quantificação direta do NADH formado foi validado com sucesso. A próxima etapa envolverá a imobilização da enzima em capilares de sílica fundida e o emprego deste método cromatográfico para o desenvolvimento de ensaios cinéticos e do método de triagem proposto.

\section{Agradecimentos FAPERJ e CNPq.}

\section{Referências Bibliográficas}

1. PISSINATE, Kenia et al . Synthesis and Evaluation of Thiazolyl-1Hbenzo[d]imidazole Inhibitors of Mycobacterium tuberculosis Inosine Monophosphate Dehydrogenase. J. Braz. Chem. Soc., São Paulo, 


\section{Artigo Geral 21}

v. 26, n. 7, p. 1357-1366, July 2015.

2. Brasil. Resolução RDC n 166 , de 24 de julho de 2017. ANVISA Agência Nacional de Vigilância Sanitária.

\section{Mariana Delle Piane de Carvalho \& Marcela Cristina de Moraes*}

Departamento de Química Orgânica, Instituto de Química, UFF

*E-mail: mcmoraes@id.uff.br 